\title{
Acetalization of Hexanal with 2-Ethyl Hexanol Catalyzed by Solid Acids
}

\author{
Alessandro O. Barros, Aline T. Faísca, Elizabeth R. Lachter,* \\ Regina S. V. Nascimento and Rosane A. S. San Gil \\ Instituto de Química, Universidade Federal do Rio de Janeiro, Av. Athos da Silveira Ramos 149, CT, \\ Bloco-A, 617, Cidade Universitária, 21949-900 Rio de Janeiro-RJ, Brazil
}

\begin{abstract}
A atividade catalítica de sólidos ácidos como o fosfato de nióbio e a Amberlyst 35, uma resina trocadora de íons, foi avaliada na acetalização do hexanal com 2-etil-hexanol. Foram avaliadas a concentração do catalisador e a temperatura de reação na conversão do hexanal. A possibilidade de re-utilização do fosfato de nióbio também foi estudada e evidenciou ser possível re-utilizar este catalisador sem perda da atividade. O rendimento em acetal foi acima de $90 \%$ em condições brandas de reação.
\end{abstract}

The catalyst activity of solid acids such as niobium phosphate and Amberlyst 35, an ion exchange resin, was evaluated in the acetalization of hexanal with 2-ethyl-hexanol. The catalyst loading and the reaction temperature were evaluated in the hexanal conversions. The possibility of recycling niobium phosphate was also studied, showing that it was possible to reuse this catalyst without significant loss in its catalytic activity. The yield in acetal was above $90 \%$ under mild conditions.

Keywords: acetalization, acetals, niobium phosphate, acid solids, Amberlyst 35

\section{Introduction}

The acetalization reaction is a process intensely used in organic synthesis to protect the carbonyl group of ketones and aldehydes and it is of great synthetic utility. ${ }^{1-3}$ Acetals are prepared by the reaction of aldehydes (or ketones) with alcohols (or orthoformates) in the presence of an acid catalyst. ${ }^{1-4}$ Most of the acetalization process is the reaction of carbonyl compounds with ethylene glycol in the presence of an appropriate catalyst. ${ }^{1,5}$

Acetal derived compounds have been used as a solvent in fragrance industries, cosmetics, food and beverage additives, pharmaceuticals, in the synthesis of enantiomerically pure compounds, and in polymer chemistry. ${ }^{6,7}$ Acetals have been also used in motor oils, lubricating oils and hydraulic fluids. Hille et al., ${ }^{8}$ have evaluated various acetals as more biodegradable continuous phase in an invert-emulsion for off-shore drilling petroleum operations. Good results were achieved when the acetals of the 2-ethyl-hexanol were used. Recently our research group has evaluated alkyl acetals as invert-emulsions drilling fluids. ${ }^{9}$ The alkyl acetals were

\footnotetext{
*e-mail: lachter@iq.ufrj.br
}

synthesized through acid catalysis using $p$-toluenesulfonic acid as catalyst. ${ }^{9}$

Acid catalysts include corrosive protic acids such as hydrochloric acid $(\mathrm{HCl})$, sulfuric acid $\left(\mathrm{H}_{2} \mathrm{SO}_{4}\right)$ and $p$-toluenesulfonic acid. These homogeneous catalysts present limitations because of their toxicity, corrosiveness and non-reusability, the difficulty of the work-up procedure, and the resulting environmental pollution. Heterogeneous catalysts, on the other hand, presents easy work-up, high product purity, and the possibility of recycling catalysts and does not involve the use of dangerous substances. ${ }^{10}$ Various heterogeneous catalysts have been employed in acetalization reactions, such as zeolite, ${ }^{11,12}$ clays, ${ }^{7}$ sulfonic resins, ${ }^{13,14}$ mesoporous aluminosilicate, ${ }^{15} \mathrm{Al}\left(\mathrm{HSO}_{4}\right)_{3},{ }^{5}$ SBA- $15,{ }^{16}$ and $\mathrm{CeCl}_{3} \cdot{ }^{17}$

Considering solid catalysts with Brønsted acid sites, niobium based systems are potentially interesting. Niobium phosphate has a texture, acidic sites (Brønsted and Lewis) and catalytic properties similar to niobium oxide, but it has the advantage of conserving these properties at higher pretreatment temperatures. ${ }^{18}$ Our group has been evaluating niobium catalysts ${ }^{19}$ in benzylation and alkylation reactions and the results evidenced the high catalytic activity of niobium phosphate for these reactions..$^{20-23}$ However to the 
best of our knowledge, the use of niobium phosphate as catalysts for acetalization reactions has not been reported until now. Therefore the objective of this work is to report the performance of niobium phosphate and a comparison with Amberlyst 35 and $p$-toluenesulfonic acid in the acetalization reaction of hexanal with 2-ethyl-hexanol to prepare alkyl acetal to be used in drilling fluid research.

\section{Experimental}

\section{Materials}

Niobium phosphate (NbP), supplied by CBMM (Companhia Brasileira de Metalurgia e Mineração, Araxá, Brazil), was dried and activated at $300{ }^{\circ} \mathrm{C}$ for 2 h. Ion exchange resin, Amberlyst 35 (conceded by Rohm and Haas) was dried at $105^{\circ} \mathrm{C}$ on vacuum for $12 \mathrm{~h}$ before use. Hexanal (Acros), 2-ethyl-hexanol (VETEC), $p$-toluenesulfonic acid (VETEC) and chloroform (VETEC) were used without further purification.

\section{Surface area}

The BET surface areas and pore volumes of the niobium catalysts were determined from nitrogen adsorption isotherms at the normal boiling temperature of liquid nitrogen. The adsorption isotherms were obtained in a micromeritics ASAP (accelerated surface area and porosimetry), model 2010.

$X R D$

The niobium phosphate was characterized by X-ray powder diffraction (XRD) collected on a Miniflex Rigaku using $\mathrm{CuK} \alpha$ radiation. The samples were scanned over the angular range $8-38^{\circ}(2 \theta)$, with a step size of $0.04^{\circ}$ and a scan rate of $1 \mathrm{~s}$ per step.

\section{FTIR}

Infrared (FTIR) spectra of niobium phosphate and the acetalization product were recorded by a FTIR spectrometer (Nicolet Protegé) in the spectral range $4000-400 \mathrm{~cm}^{-1}$ using potassium bromide $(\mathrm{KBr})$ pressed disks.

\section{General acetalization procedure}

The reaction was carried out in a $25 \mathrm{~mL}$ round-bottom two necked flask outfitted with a condenser and a septum for sample removal. In a typical run, hexanal $(8 \mathrm{mmol}$, $0.8 \mathrm{~g}$ ) and 2-ethyl-hexanol (64 mmol, $8.32 \mathrm{~g}$ ) were added to the activated catalyst $(0.05 \mathrm{~g})$ previously transferred to the reaction flask. The reaction mixture was magnetically stirred at atmospheric pressure and heated by means of a constant temperature bath $\left(60^{\circ} \mathrm{C}\right)$ and at room temperature $\left(25^{\circ} \mathrm{C}\right)$. All the reactions were performed without solvent.

The degree of hexanal conversion was analyzed periodically by gas chromatography (GC) (VARIAN, 3800). The products were also identified by GC MS (HP5890 series II/HP5972 series, respectively), Fourier transform infrared (FTIR) and proton nuclear magnetic resonance ( ${ }^{1} \mathrm{H}$ NMR).

\section{Analytical procedure}

The variations of the substrate, hexanal and product contents (hexylaldehyde di-2-ethyl-hexyl acetal) were carried using a VARIAN model 3800 gas chromatograph equipped with a hydrogen flame ionization detector system and a capillary column (VA-5, $30 \mathrm{~m}, 0.32 \mathrm{~mm}$ i.d. $1 \mu \mathrm{m}$ d.f). The temperature was programmed from 40 to $280^{\circ} \mathrm{C}$ with hydrogen $\left(\mathrm{H}_{2}\right)$ as the carrier gas at a rate of $2 \mathrm{~mL} \mathrm{~min}^{-1}$. Aldehyde conversion was calculated taking into account the response factor which was determined experimentally.

The identification of the products obtained in the acetalization reaction was carried out by gas chromatography mass spectrometry analysis (GC MS) on a HP 6890, utilizing a DB-5 $(30 \mathrm{~m})$ fused silica column at the same temperature conditions with helium $(\mathrm{He})$ as the carrier gas.

FTIR spectra of reaction products were determined on a Magna-IR 760, NICOLET. Nuclear magnetic resonance spectra were recorded on a BRUKER DRX-200 $(200 \mathrm{MHz}$ for $\left.{ }^{1} \mathrm{H}\right) .{ }^{1} \mathrm{H}$ chemical shifts $(\delta)$ in $\mathrm{CDCl}_{3}$ are given from internal tetramethylsilane (TMS).

Typical procedure for preparation of hexylaldehyde di2-ethyl-hexyl acetal catalysed by p-toluenesulfonic acid under reflux conditions

The reaction was carried out in a $25 \mathrm{~mL}$ round-bottom two necked flask outfitted with a condenser and a septum for sample removal. In a typical run, hexanal $(8 \mathrm{mmol}, 0.8 \mathrm{~g})$, 2-ethyl-hexanol (64 mmol, $8.32 \mathrm{~g})$ and chloroform $(10 \mathrm{~mL})$ were added to the $p$-toluenesulfonic acid $(0.16 \mathrm{mmol}$, $0.027 \mathrm{~g}$ ). The reaction mixture was magnetically stirred at atmospheric pressure and heated to reflux by means of a constant temperature bath $\left(60^{\circ} \mathrm{C}\right)$. A Dean Stark apparatus was used in order to remove the water formed along the reactions' process. ${ }^{8}$ Chloroform was chosen, despite its poor azeotrope with water, to maintain the reaction temperature below $70{ }^{\circ} \mathrm{C}$ as described in the literature. ${ }^{8,9}$ In this case the Dean Stark was emptied from time to time. After the 
completion of the reaction (monitored by CG for conversion and selectivity) the sample was washed with water, and the organic phase (acetal) was dried with magnesium sulfate and submitted to distillation to remove the chloroform and the alcohol. The yield was $98 \%$. Spectroscopic data of hexylaldehyde-di-2-ethylhexyl acetal, IR (KBr) $v_{\max } / \mathrm{cm}^{-1} 2958-2800$ (s) (-CH stretching), 1128 and 1047 (s) (C-O, stretching). ${ }^{1} \mathrm{H}$ NMR $\left(200 \mathrm{MHz}, \mathrm{CDCl}_{3}\right) \delta 0.89$ (t, $4 \mathrm{~Hz}, 15 \mathrm{H}), 1.37(\mathrm{~m}, 22 \mathrm{H}), 1.6(\mathrm{~m}, 4 \mathrm{H}), 3.3(\mathrm{~m}, 2 \mathrm{H})$, $3.45(\mathrm{~m}, 2 \mathrm{H}), 4.42(\mathrm{t}, 6 \mathrm{~Hz}, 1 \mathrm{H})$.

\section{Results and Discussion}

Table 1 reports characterization and acidity data of the heterogeneous catalysts used in the acetalization reaction.

Table1. Surface areas and acidity of the catalysts

\begin{tabular}{lcc}
\hline Catalyst & $\mathrm{S}\left(\mathrm{m}^{2} \mathrm{~g}^{-1}\right)$ & Acidity $^{\mathrm{a}}\left(\mathrm{mmol} \mathrm{g}^{-1}\right)$ \\
\hline Amberlyst 35 & 50 & $5.2^{\mathrm{a}}$ \\
Niobium phosphate & 138 & $0.24^{\mathrm{b}}$ \\
\hline
\end{tabular}

${ }^{\mathrm{a} A m o u n t}$ of $\mathrm{SO}_{3} \mathrm{H}$ on the surface. Data informed by the producer; ${ }^{\mathrm{b}}$ total acidity measured by n-propylamine adsorption at $423 \mathrm{~K} .{ }^{21,24}$

The commercial niobium phosphate presents reasonable value of specific area, $138 \mathrm{~m}^{2} \mathrm{~g}^{-1}$ and lower acidity than Amberlyst 35 .

The data obtained by XRD analysis showed that the niobium phosphate used in this work was amorphous. ${ }^{21-24}$ The IR spectrum of the niobium phosphate show a strong band due to the asymmetric vibration stretching mode of phosphate ion with a maximum at $1010 \mathrm{~cm}^{-1}$. An additional strong band is found at $620 \mathrm{~cm}^{-1}$ in agreement with the spectrum of niobic acid, which could be due to $\mathrm{Nb}-\mathrm{O}$ stretching modes. ${ }^{20,21}$ Py-FTIR characterization of the niobium phosphate indicated the presence of Brønsted acid sites (BAS) and Lewis acid sites (LAS) as shown in previous works. ${ }^{21,24}$ The concentration of Lewis and Brønsted sites in commercial niobium phosphate was evaluated by FTIR of pyridine adsorbed at different temperatures in a previous paper. ${ }^{20}$ Weak sites are defined as the ones from which pyridine is removed by evacuation at $423 \mathrm{~K}$; the medium strength corresponds to evacuation between 473 and $573 \mathrm{~K}$ and the strong sites remain adsorbing pyridine after evacuation at $673 \mathrm{~K}$. The niobium phosphate has a large amount of medium (11.63 $\left.\mathrm{mmol} \mathrm{g}^{-1}\right)$ than weak $\left(2.89 \mathrm{mmolg}^{-1}\right)$ or strong $\left(1.81 \mathrm{mmol} \mathrm{g}^{-1}\right) \mathrm{BAS}^{20}$

The reaction of hexanal with 2-ethyl-hexanol is presented in Scheme 1. The reaction mixture (hexanal with 2-ethyl-hexanol) was magnetically stirred at atmospheric pressure over the acid solids without solvent. The reaction catalyzed by $p$-toluenesulfonic acid a Dean Stark apparatus was used in order to remove the water formed along the reaction process. ${ }^{8}$ In the effect of the molar ratio of hexanal/ alcohol, the calcinations temperature of the niobium phosphate, the reaction temperature and reutilization of the catalysts were also studied.

\section{Acetalization reaction catalyzed by Amberlyst 35}

The results obtained in the reaction over Amberlyst 35 are presented in Table 2.

The results have shown that in the reaction at room temperature, an increase in molar ratio aldehyde/alcohol no significantly increase the hexanal conversion (entries 1, 2 and 3) after $3 \mathrm{~h}$.

The effect of the catalyst loading in the conversion of the hexanal to hexylaldehyde di-2-ethyl-hexanol is shown in Table 2 (entries 3, 4 and 5). The overall reaction rate was found to increase along with the increase of the catalyst loading in the range employed in this work. An increase in the catalyst loading results in an increase in the number of Bronsted sites, which leads to the formation of a protonated hexanal per unit of time and increases the reaction rate.

The acetalization of hexanal with 2-ethyl-hexanol was carried at temperature of $60{ }^{\circ} \mathrm{C}$ and room temperature (solvent free conditions). The results show (Table 2,

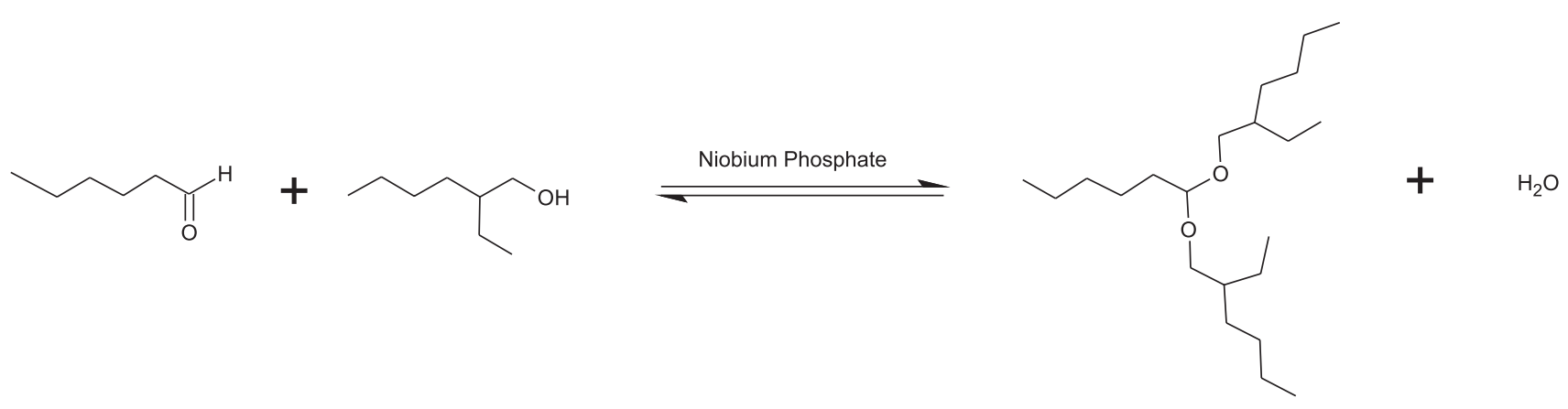


Table 2. Acetalization of hexanal with 2-ethyl hexanol over Amberlyst 35

\begin{tabular}{lccccc}
\hline Entry & $\begin{array}{c}\text { Molar Ratio } \\
\text { aldehyde/alcohol }\end{array}$ & $\begin{array}{c}\text { Catalyst Amount } \\
(\mathrm{g})\end{array}$ & $\begin{array}{c}\text { time } \\
(\mathrm{h})\end{array}$ & $\begin{array}{c}\text { Temperature } \\
\left({ }^{\circ} \mathrm{C}\right)\end{array}$ & $\begin{array}{c}\text { Hexanal Conversion } \\
(\%)\end{array}$ \\
\hline 1 & $1 / 4$ & 0.1 & 3 & 25 & 90 \\
2 & $1 / 6$ & 0.1 & 3 & 25 & 90 \\
3 & $1 / 8$ & 0.1 & 3 & 25 & 94 \\
4 & $1 / 8$ & 0.05 & 3 & 25 & 76 \\
5 & $1 / 8$ & 0.01 & 1 & 25 & 42 \\
6 & $1 / 8$ & 0.05 & 3 & 60 & 99 \\
$7^{\text {a }}$ & $1 / 8$ & 0.1 & & 25 & 80 \\
\hline
\end{tabular}

aRe-utilization.

entries 4 and 6) that increases in the reaction temperature result in an increase in the conversion of the hexanal in the hexylaldehyde di-2-ethyl-hexanol and a total conversion was obtained after $1 \mathrm{~h}$. The re-utilization of Amberlyst 35 was evaluated at room temperature and the results have shown that the conversion decreased after the second utilization (Table 2, entries 3 and 7).

\section{Acetalization reaction catalyzed by niobium phosphate}

The effect of the activation temperature of niobium phosphate was evaluated in the conversion of the aldehyde in acetal (Figure 1) using a amount of $0.05 \mathrm{~g}$ of the catalyst. The temperature had varied from 150 to $300{ }^{\circ} \mathrm{C}$. The reactions were carried at the temperature of $60^{\circ} \mathrm{C}$.

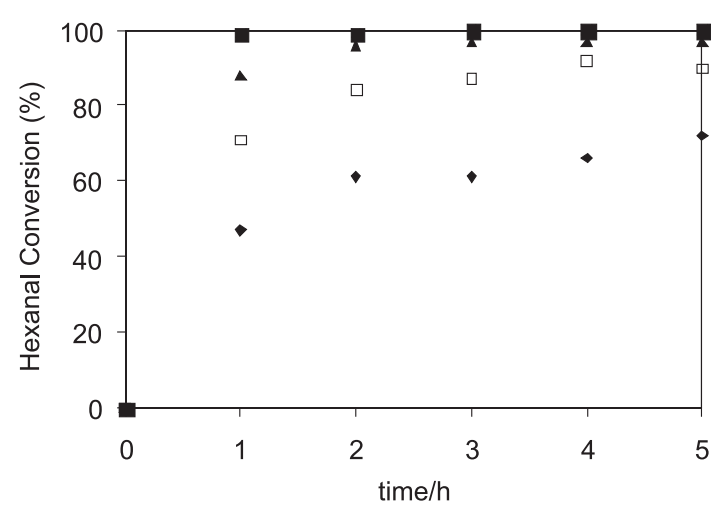

Figure 1. Effect of calcination temperature of niobium phosphate on the acetalization reaction. Conditions: hexanal/alcohol (1/8), temperature $=60^{\circ} \mathrm{C}, 0.05 \mathrm{~g}$ of catalyst; $\quad 300^{\circ} \mathrm{C}, \boldsymbol{\Delta} 250^{\circ} \mathrm{C}, \square 200^{\circ} \mathrm{C}$, $\bullet 150{ }^{\circ} \mathrm{C}$.

We verified that an increase in the calcination temperature results in an increase in the conversion of the hexanal. The best results were achieved at a temperature of $300^{\circ} \mathrm{C}$. In this case the increase of calcination temperature removed the water present in the catalyst and increases the acid sites strength. ${ }^{18,21}$

The effect of reaction temperature was evaluated and the results were presented in Table 3 .
Table 3. Acetalization of hexanal with 2-ethyl hexanal over niobium phosphate ${ }^{a}$, effect of reaction temperature

\begin{tabular}{lccc}
\hline Entry & $\begin{array}{c}\text { Temperature } \\
\left({ }^{\circ} \mathrm{C}\right)\end{array}$ & $\begin{array}{c}\text { Catalyst amount } \\
(\mathrm{g})\end{array}$ & $\begin{array}{c}\text { Hexanal } \\
\text { Conversion }(\%)\end{array}$ \\
\hline 1 & 60 & $0.05^{\mathrm{b}}$ & 100 \\
2 & 60 & $0.025^{\mathrm{c}}$ & 100 \\
3 & 25 & $0.5^{\mathrm{d}}$ & 88 \\
$4^{\mathrm{e}}$ & 25 & $0.5^{\mathrm{d}}$ & 84 \\
\hline
\end{tabular}

${ }^{\mathrm{a} N i o b i u m}$ phosphate calcinated at $300^{\circ} \mathrm{C}$; ${ }^{\mathrm{b}} 3 \mathrm{~h}$; ${ }^{\mathrm{c}} 4, \mathrm{~h}$; ${ }^{\mathrm{d}} 5 \mathrm{~h}$ and ${ }^{\mathrm{e}}$ re-utilization.

When the reaction was carried out at lower temperature, the conversion was above $88 \%$ (Table 3 , entry 3 ) after $300 \mathrm{~min}$. The selectivity in acetal product was $100 \%$ in all cases. Following a worldwide trend of the development of green catalysts, the reutilization of phosphate niobium in acetalization reactions (Table 3, entries 3 and 4) is possible at solvent free condition. The reutilization of the catalyst keeps the conversion of the reaction at $84 \%$.

The reaction catalyzed by $p$-toluenosulfonic acid was carried out at reflux temperature of solvent as described in the literature. ${ }^{8,9}$ The yield in hexylaldehyde di-2-ethylhexayl acetal was $98 \%$ after $1 \mathrm{~h}$.

The comparison of the three catalysts is presented in Table 4. The use of niobium phosphate as catalyst results in higher turnover number than $p$-toluenesulfonic acid and sulfonic acid resin.

Acetalization occurs in the presence of Brønsted acids. The protonation of the oxygen atom on the carbonyl group by an acidic site from the catalytic surface of niobium

Table 4. Acetalization of hexanal with 2-ethyl hexanal over niobium phosphate and Amberlyst 35 catalysts

\begin{tabular}{|c|c|c|c|}
\hline Catalyst & $\begin{array}{l}\text { Catalyst Amount } \\
\text { (g) }\end{array}$ & $\begin{array}{c}\text { Hexanal } \\
\text { conversion (\%) }\end{array}$ & $\mathrm{TON}^{\mathrm{a}}$ \\
\hline Niobium Phosphate ${ }^{b, c}$ & 0.025 & 98 & 1306 \\
\hline Amberlyst $35^{\mathrm{c}}$ & 0.05 & 99 & 30.5 \\
\hline$p$-toluenesulfonic acid ${ }^{\mathrm{d}}$ & 0.027 & 98 & 49 \\
\hline
\end{tabular}

${ }^{\mathrm{a}} \mathrm{TON}=$ mmol acetal $\mathrm{mmol}^{-1}$ acid sites; ${ }^{\mathrm{b}} \mathrm{Calcination}$ temperature $=300{ }^{\circ} \mathrm{C}$;

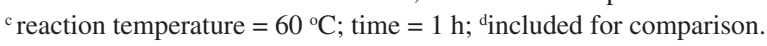


phosphate can be considered the initial step that enables a subsequent nucleophilic attack by an alcohol molecule. After hemiacetal formation it could be protonated, losing water and suffering a new nucleophilic attack by the alcohol. The loss of a proton from the surface of the catalyst yields the acetal. Although the number of acid sites of niobium phosphate are lower compared with Amberlyst 35, the former presented sites with acid strength of $\mathrm{H}_{0} \leq 8.2$ as described by Martins et al. ${ }^{25}$ The ion exchange resin present lower acid strength $\left(\mathrm{H}_{0} \leq 2.2\right){ }^{26}$

Shimizu et al., ${ }^{27}$ studied the acetalization of different carbonyl compounds with ethylene glycol over solids acids. They compared the catalytic activity of zeolites, clay, sulfonic acid functionalized mesoporous silica and the sulfonic resin Amberlyst 15. The results showed better yield in acetal with the sulfonic acid functionalized mesoporous silica. In the reaction of octanal with ethylene glycol and toluene as solvent, the aldehyde conversion was $99 \%$ after $3 \mathrm{~h}$. The resin Amberlyst 15 showed lower rate and the authors related this result to the low accessibility of the reactant to the acid sites inside the resin that presented lower specific area than mesoporous silica. Another factor that could affect the acetalization reaction is the strength of the Bronsted acid sites. Although the Amberlyst 15 presented large number of acid sites $\left(4.8 \mathrm{mmol} \mathrm{g}^{-1}\right)$ than mesoporous silica $\left(0.43 \mathrm{mmol} \mathrm{g}^{-1}\right)$ the latter was more efficient for acetalization reaction. They conclude that the number of acid sites per gram of the catalyst is not necessarily for acetal formation and the high activity of the silica should be due the strong Brønsted acid sites inside the mesopore and higher specific areas. ${ }^{27}$

In this work the higher performance of niobium phosphate compared with Amberlyst 35 could be due to the acid strength of the Brønsted acid sites and the higher specific area of the former in accordance with the results reported by Shimizu et al. ${ }^{27}$

\section{Conclusions}

The present work demonstrates that niobium phosphate is a highly effective and re-usable catalyst for the acetalization of hexanal with 2-ethyl-hexanol under mild conditions in solvent free conditions.

\section{Acknowledgments}

The authors would like to thank the CNPq and ANP for their financial support.

\section{References}

1. Whitesel, J. K.; Chem. Rev. 1989, 89, 1581.
2. Nieddu, E.; Cataldo, M.; Pinna, F.; Strukul, G.; Tetrahedron Lett. 1999, 40, 6987.

3. Green, T. W.; Wuts, P. G. M.; Protective Group in Organic Synthesis; John Wiley and Sons: New York, 1999.

4. Wiles, C.; Watts, P.; Haswell, S. J.; Tetrahedron 2005, 61, 5209.

5. Mirjalili, B. F.; Zolfigol, A. M.; Bamoniri, C. A.; Hazar, A.; J. Braz. Chem. Soc. 2005, 16, 877.

6. Capeletti, M. R.; Balzano, L.; Puentes, G. M.; Appl. Catal., A 2000, 198, L1.

7. Thomas, B.; Prathapan, S.; Sugunan, S.; Microporous Mesoporous Mater. 2005, 80, 65.

8. Hille, M.; Wittkus, H.; Scholz, H. J.; Weinelt, F.; US pat. 5,759,963 1998.

9. Barros, A. O.; Procedings of the IVPDPETRO 2007. http:// www.portalabpg.org.br/PDPetro/4/resumos/4PDPETRO_2_2_ 0074-1.pdf, accessed in January 2010 (text in Portuguese).

10. Ballini, R.; Bosica, G.; Frullanti, B.; Raimondo, M.; Giovanni, G.; Sartori, S.; Schroer, F.; Tetrahedron Lett. 1999, 39, 1615.

11. Thomas, B.; Sugunan, S.; J. Porous Mater. 2006, 13, 99.

12. Da Silva, C. X. A.; Gonçalves, V. L. C.; Mota, C. J. A.; Green Chem. 2009, 11, 38.

13. Gelbard, G.; Ind. Eng. Chem. Res. 2005, 44, 8468.

14. Mahajani, S. M.; Kolah, A. K.; Sharma, M. M.; React. Funct. Polym. 1995, 28, 29.

15. Robinson, M. W.; Graham, A. E.; Tetrahedron Lett. 2007, 48, 4727.

16. Mayoral, E. P.; Martin-Aranda, R. M.; Lopez-Peinado, A. J.; Ballesteros, P.; Zukal, A.; Cejka, J.; Top. Catal. 2009, 52, 148.

17. Silveira, C. C.; Mendes, S. R.; Ziembowiscz, F. I.; Lenardão, E. J.; Perin, G.; J. Braz. Chem. Soc. 2010, 21, 371.

18. Nowak, I.; Ziolek, M.; Chem. Rev. 1999, 99, 3603.

19. De la Cruz, M. H. C.; Abdel-Rehim, M. A.; Rocha, A. S.; Da Silva, J. F. C.; Faro, A. C.; Lachter; E. R.; Catal. Commun. 2007, 8, 1650.

20. Rocha, A. S, Forrester A. M. S; De la Cruz M. H. C.; Da Silva C. T.; Lachter, E. R.; Catal. Commun. 2008, 9, 1959.

21. Pereira, C. C. M.; Lachter, E. R.; Appl. Catal., A 2004, $266,67$.

22. De la Cruz, M. H. C.; Da Silva, J. F. C.; Lachter, E. R.; Catal. Today 2006, 118, 379.

23. Pereira, C. C. M.; De La Cruz, M. H. C.; Lachter, E. R.; J. Braz. Chem. Soc. 2010, 21, 367.

24. de la Cruz, M. H. C;; da Silva, J. F. C.; Lachter, E. R.; Appl. Catal. A 2003, 245, 377.

25. Martins, R. L.; Schitina, W. J.; Castro, F. R.; Catal. Today 1989, $5,483$.

26. Olah, G. A.; Prakash, G. K. S.; Sommer, J.; Superacid, Wiley: New York, 1985.

27. Shimizu, K.; Hatamachi, T.; Kodama, T.; Higuchi, Y.; Satsuma A.; Kitayama, Y.; J. Catal. 2005, 231, 131. 